\title{
Hydrogen Chloride in Fires
}

\author{
T RICHARD HULL, ANNA A STEC and KEITH T PAUL \\ Centre for Fire and Hazards Science \\ School of Forensic and Investigative Sciences \\ University of Central Lancashire \\ Preston, Lancashire, PR1 2HE, UK
}

\begin{abstract}
ISO 13571:2007 describes the calculation of safe escape time using yields of asphyxiant and irritant gases for performance based design. Hydrogen chloride $(\mathrm{HCl})$ gas is an incapacitating irritant, reported to be intolerable at concentrations above $100 \mathrm{ppm}$, but lethal to rats only at concentrations around 5000ppm for a 30 minute exposure. It is evolved from burning PVC, and other chlorine containing plastics. The experimental evidence of the concentration/dose effects on a range of animal species has been reviewed, and concludes that the $\mathrm{HCl}$ concentration leading to incapacitation of $1000 \mathrm{ppm}$, used in ISO 13571, is rather too high to ensure safe escape. Experimental data is presented from burning unplasticised PVC, plasticized PVC cable, and LDPE to show that $\mathrm{HCl}$ interferes with the flame chemistry, particularly the conversion of $\mathrm{CO}$ to $\mathrm{CO}_{2}$, further increasing the hazard from the fire effluent. The product yields are used to estimate the fire effluent toxicity, comparing the standard based on rat lethality, ISO 13344 with the newer standard, which also takes the effect of incapacitating irritants into account, showing the large contribution of $\mathrm{HCl}$ to the fire hazard. Finally, the relationship between the toxicity and a simple analysis of effluent acidity (EN 50297-2-3) is discussed.
\end{abstract}

KEYWORDS: fire chemistry, toxicity, egress

\section{INTRODUCTION}

The prediction of the hazards to life of people from exposure to fire effluents, including heat, smoke and toxic gases, is an important part of fire hazard assessment and fire safety engineering. The acceptance of ISO 13571 [1] provides the tools to assess hazard to life during escape from a fire for performance based design, and establishes a framework against which the fire safety provided by regulatory codes can be quantified. Specifically, it describes methods for calculation of the time available for escape, which it defines as the interval between ignition and when the conditions become untenable, preventing occupants from taking effective action to accomplish their own escape. It describes such incapacitation as resulting from:

a) exposure to radiant and convected heat;

b) inhalation of asphyxiant gases, such as carbon monoxide (CO) and hydrogen cyanide ( $\mathrm{HCN})$;

c) exposure to sensory/upper-respiratory irritants, including acid gases and organoirritants;

d) visual obscuration due to smoke.

The aim of this study is to consider the hazards associated with hydrogen chloride $(\mathrm{HCl})$ in fire effluents and the extent to which they contribute to the overall prediction of fire toxicity. First, it is necessary to review the available information on the effects of exposure to $\mathrm{HCl}$ on human and animal subjects. Then, using polyvinyl chloride (PVC) as an example with well-characterised decomposition and combustion products, the effects of $\mathrm{HCl}$ as a component of fire gas are considered. How this information may be input into sets of equations for predicting the fire gas toxicity is described. However, for substances such as $\mathrm{HCl}$, which can deposit rapidly, not only on walls and surfaces of enclosures, but also on water droplets and smoke particles, the transport of $\mathrm{HCl}$ in fire effluents must also be considered. A method for quantifying the yields of toxic products in fire effluents as a function of fire condition is described, alongside a method adopted by the European Commission for classification of cable materials according to the acidity of their decomposition products. Experimental data is reported showing the influence of $\mathrm{HCl}$ on the $\mathrm{CO}$ yield under different fire conditions, and how these combinations of toxicants translate into an overall estimation of the toxicity. Finally, a relationship between the European acidity classification and the fire toxicity for a number of electric cables burned under well-ventilated conditions is reported. 
Sensory irritants cause painful effects to the eyes, upper respiratory tract, and to the lungs. The ratio between the concentrations producing severe irritation and death is typically between 15 and 500 [2]. Moreover, experiments exposing human subjects to CS gas (2-chlorobenzalmalononitrile) [3], which produces similar symptoms to $\mathrm{HCl}$ exposure, indicate that a gradual increase in concentration would allow subjects to tolerate a concentration which would be unbearable when subjected to immediate exposure. It has been argued both that sensory irritants will provide a stimulus to encourage escape [4], or that they will make escape extremely difficult [5]. Given the range of responses of human fire victims, it is likely that some individuals will respond by furthering their efforts to escape, while others, feeling unable to see or breathe, will be trapped. This raises the question as to what is an acceptable proportion of a population we can allow to be trapped in a fire, and what concentration of irritant gas will produce this?

\section{EFFECTS OF HCI ON HUMAN SUBJECTS}

Hydrogen chloride $(\mathrm{HCl})$ is an acid gas which causes severe irritant effects at low concentrations (around $100 \mathrm{ppm}$ ) but only results in death at very high concentrations (in mice $2600 \mathrm{ppm}$, rats $4700 \mathrm{ppm}$ for 30 minute exposures [6]). The difficulty in quantifying a threshold level for incapacitation, and the high levels of $\mathrm{HCl}$ evolved during decomposition of certain materials has led to a long-running controversy over the maximum atmospheric concentrations of $\mathrm{HCl}$ in fire gas from which escape is still possible.

There is only one report of human exposure to $\mathrm{HCl}$ gas at concentrations relevant to fires [7], which found that humans could tolerate exposure to $10 \mathrm{ppm} \mathrm{HCl}$, while at 70 and $100 \mathrm{ppm}$ humans had to leave the room because of intense irritation, coughing and chest pains, indicating that $100 \mathrm{ppm}$ is intolerably irritating to humans. That data has led to guidelines [8] that the maximum concentration tolerable for 1 hour is between 50 and $100 \mathrm{ppm}$, and that 1000 to $2000 \mathrm{ppm}$ is dangerous for even short exposures. These guidelines were corroborated using an animal model that properly predicted intolerable irritation levels for humans for other inorganic gases such as sulphur dioxide, ammonia, chlorine, and a wide variety of organic chemicals, including formaldehyde, acrolein, etc., [9], [10] indicating that $300 \mathrm{ppm}$ would be intolerable to humans [11].

Table 1 summarises the expected effects of $\mathrm{HCl}$ on humans [12] confirming that concentrations of 50 to $100 \mathrm{ppm}$ are barely tolerable for exposures up to an hour, while exposure to concentrations of $1000 \mathrm{ppm}$ of $\mathrm{HCl}$ would be dangerous, causing lung oedema after only a few minutes exposure.

Table 1. Inhalation exposure of humans to hydrogen chloride [12].

\begin{tabular}{|c|l|l|l|}
\hline $\begin{array}{l}\text { Approximate } \\
\text { Concentration } \\
\text { /ppm }\end{array}$ & $\begin{array}{l}\text { Exposure } \\
\text { time }\end{array}$ & Effect & Ref \\
\hline 1 to 5 & & Limit of detection by odour & \\
\hline$\geq 5$ & Unspecified & Immediately irritating & {$[13]$} \\
\hline$>10$ & Occupational & $\begin{array}{l}\text { Highly irritating, although workers develop some } \\
\text { tolerance }\end{array}$ & {$[13]$} \\
\hline 10 & Prolonged & Maximum tolerable & {$[8]$} \\
\hline 10 to 50 & A few hours & Maximum tolerable & {$[8]$} \\
\hline 35 & Short & Throat irritation & {$[8]$} \\
\hline $50-100$ & 1 hour & Maximum tolerable & {$[8]$} \\
\hline $1000-2000$ & Short & Dangerous & {$[8]$} \\
\hline
\end{tabular}

However, it has also been argued that sensory irritancy is dependent on concentration, not dose [14]. Since the response, like a blinding light or deafening sound is practically instantaneous, the exposure times in Table 1 may be inappropriate.

\section{EFFECTS OF HCI ON ANIMAL SUBJECTS}

A number of methods have been used to indicate incapacity [15], [16]. While lethality studies inevitably provide the most reproducible end point, behavioural end-points for incapacity are more difficult to define, and are generally too close to death, or require extensive training [15], [17]. A number of studies have 
been undertaken exposing animals to $\mathrm{HCl}$ to address the issue of $\mathrm{HCl}$ in fire gases. These studies are compromised by the difficulty in relating irritancy suffered by the animal to a human equivalent, the difficulty in defining the point at which incapacitation occurs, and by the apparent tolerance developed during the period of exposure. In mammals, the trigeminal and vagus nerves respond to acidic irritant gases, in mice this leads to a fall in respiration rate to $10 \%$ of its normal value, while in primates and humans [2], as the lungs become flooded with pulmonary fluid, their decreased efficiency results in hyperventilation.

The guinea-pig has been proposed as the most appropriate model to use to study the effect of $\mathrm{HCl}$ because this animal, like humans, is known to develop laryngeal and bronchial spasms leading to suffocation [18]. Guinea-pigs have been exposed to $\mathrm{HCl}$ at rest and during moderate exercise [19]. Incapacitation occurred very quickly $(60 \mathrm{~s})$ at $600 \mathrm{ppm}$ during exercise followed by death due to suffocation, as suggested [18]. In contrast, in one study when mice were exposed to various $\mathrm{HCl}$ concentrations in motorised wheels [20], incapacitation resulted from exposure to $20000 \mathrm{ppm} \mathrm{HCl}$ between 5 and 15 minutes, and at $10000 \mathrm{ppm}$ from 17 minutes upwards.

Crane et al. observed that much higher $\mathrm{HCl}$ concentrations (e.g. $13000 \mathrm{ppm}$ lead to incapacitation in 30 minutes and death in 36 minutes) were required for incapacitation of rats, also on a motorised wheel [21]. The mechanism of action for $\mathrm{HCl}$ in rats, based on observations during this study, seems to be primarily one of mechanical blockage of the upper airways caused by the extreme inflammatory and corrosive action of this strong mineral acid on these tissues. Post-mortem examination indicated almost total destruction from the nasal passage to the pharynx, but surprisingly little damage to airways below the trachea. Amongst obligatory nose-breathers, the lower sensitivity of rats than mice to $\mathrm{HCl}$ has been ascribed to differences in their nasal passages. When a tube was used to bypass these passages, the response of rats occurred at similar concentrations to those of mice [22]. This has led to the suggestion that species that breathe through their mouth (humans, especially in the stressful situation of escaping from a fire) may be more sensitive to the effects of $\mathrm{HCl}$ than obligate nasal breathers, such as rodents [12].

Much of the controversy surrounding survivable $\mathrm{HCl}$ concentrations revolves around two studies in which baboons were exposed to dry $\mathrm{HCl}$. The first study focussed on a simple escape paradigm [23], the second measured their respiratory changes [24]. The baboons used for the first test series were trained for 5 to 8 weeks to respond with $95 \%$ success by distinguishing a correct white lever in response to a white light, from an incorrect red lever and red light, "encouraged" by a sound, and then an electric shock. Both those animals which operated the lever and escaped within 10 seconds (avoid result), and those which received the electric shock and escaped within the next 20 seconds (escape result), were considered to have escaped, and not to be incapacitated by exposure to the gas. While the irritant gas may adversely affect breathing, general well-being and the recognition of a light, it will not directly affect recognition of the sound or the electric shocks until the effects are very extreme. Indeed, there is no need to see the light as there is a $50 \%$ chance of pressing the correct lever and escaping at the first attempt. In one test at high concentrations, the incorrect lever was pushed 8 times before the correct one was pushed resulting in an escape.

Test data show that the baboons were adversely affected by $\mathrm{HCl}$ concentrations above 940 to $2780 \mathrm{ppm}$. Even higher concentrations did not prevent their escape but did adversely affect their reaction times and performance. Although the two highest concentrations did not prevent escape, these animals subsequently died from their exposure to $\mathrm{HCl}$, (classified as an escape result in the test). Understandably, each $\mathrm{HCl}$ exposure test only involved a single baboon, thus the results are not from replicated tests. This must be considered when interpreting such results. Many of the relative standard deviation values given in the baboon study are large and greater than $50 \%$ making it very difficult to draw meaningful conclusions from the data. Since the response of a population to an irritant would follow a log-normal distribution[1] with a wide range at its base, it is very difficult to see where to fit individual results into that distribution.

With the exception of the lowest $\mathrm{HCl}$ concentration (190 ppm), the baboons were all reported to cough and froth at the mouth at the lower concentrations, with profuse salivation, blinking, rubbing of the eyes and shaking of the head at the higher concentrations.

\section{PVC DECOMPOSITION AND COMBUSTION}

At elevated temperatures $\left(200-300^{\circ} \mathrm{C}\right) \mathrm{PVC}$ undergoes a dehydrochlorination reaction to release hydrogen chloride and forms a conjugated polyene [25] which undergoes further rearrangements and product 
elimination at higher temperatures to produce a complex pattern of hydrocarbons with aromatic materials predominating. Approximately 70 compounds [26] including benzene, toluene, xylene, indene, and naphthalene have been identified, but among these $\mathrm{HCl}$ is the principal toxicant. There has sometimes been an assumption that the chlorine content of burning $\mathrm{PVC}$ is quantitatively converted into $\mathrm{HCl}$ but this is not generally the case. Although some chlorine will always appear as $\mathrm{HCl}$, other chlorine containing gas or vapour species will be produced while, in some formulations, some chlorine may remain in the char. For example calcium carbonate, a common filler in $\mathrm{PVC}$, will react with $\mathrm{HCl}$ to produce non-volatile calcium chloride. A number of chlorine containing species have been identified from large-scale fires burning a high proportion of PVC, including mono- and dichlorobenzenes and other chloro-aromatic and chloroaliphatic hydrocarbons [27]. Evidence exists to show that, depending on the fire situation, as much as $20 \%$ of the chlorine may exist in an organic form [28].

\section{EFFECTS OF PVC DECOMPOSITION AND COMBUSTION PRODUCTS ON ANIMAL SUBJECTS}

When Swiss-Webster mice were exposed for 3 to 5 minutes and the sensory irritation response (measured as the change in respiratory rate) was compared with similar experiments using $\mathrm{HCl}$ [11], the PVC products were more potent sensory irritants than $\mathrm{HCl}$. In a comparison of the irritant effects of PVC from flaming and non-flaming with corresponding amounts of $\mathrm{HCl}$ alone, it was found for baboons that the respiratory rate, tidal volume and minute volume all increased dramatically, again indicating the presence of other respiratory irritants in PVC fire effluents [29].

\section{PREDICTION OF FIRE EFFLUENT TOXICITY}

The majority of UK deaths in fire are attributed to inhalation of toxic gases [30]. Carbon monoxide and hydrogen chloride are the principle toxicants from burning unplasticised PVC [31] (uPVC). There is a large variation in the responses to animal exposure to $\mathrm{HCl}$ and $\mathrm{PVC}$ fire effluents. In order to predict the escape time, it is necessary to estimate the fire toxicity, either directly from animal exposure experiments which are unacceptable in the European Union [32], or by chemical quantification of the major toxicologically significant products. ISO have published two standard methods for estimating the fire effluent toxicity from fire effluent composition. One is based on rat lethality data (ISO 13344 [33]) but which gives no indication as to how this data may be extrapolated to human exposure, while the other, which includes sensory irritants, is based on consensus estimates of human exposure limits (ISO 13571 [1]). The general approach is to assume additive behaviour of individual toxicants, and to express the concentration of each as its fraction of the lethal concentration for $50 \%$ of the population $\left(\mathrm{LC}_{50}\right)$. Thus a Fractional Effective Dose (FED) equal to one indicates that the sum of concentrations of individual species will be lethal to $50 \%$ of the population over a 30 minute exposure.

$$
\mathrm{FED}=\frac{m[\mathrm{CO}]}{\left[\mathrm{CO}_{2}\right]-b}+\frac{21-\left[\mathrm{O}_{2}\right]}{21-\mathrm{LC}_{50, \mathrm{O}_{2}}}+\frac{[\mathrm{HCN}]}{\mathrm{LC}_{50, \mathrm{HCN}}}+\frac{[\mathrm{HCl}]}{\mathrm{LC}_{50, \mathrm{HCl}}}+\frac{[\mathrm{HBr}]}{\mathrm{LC}_{50, \mathrm{HBr}}}+\ldots
$$

Equation 1, from ISO 13344, referred to as the N-Gas model, uses this approach. However, in the first term the effect of the $\mathrm{CO}$ is enhanced by the increase in respiration rate caused by high concentrations of $\mathrm{CO}_{2}$, (expressed as a step function with one value of constants $m$ and $b$ for $\mathrm{CO}_{2}$ concentrations below $5 \%$ and another for those above 5\%). The equation also includes a term for oxygen depletion, although it is generally accepted that death from other fire gas components is inevitable if the fire gas is so undiluted that the contribution from hypoxia is significant. The $\mathrm{HCN}, \mathrm{HCl}$ and $\mathrm{HBr}$ terms are the ratio of the gas concentration to the lethal concentration of $\mathrm{HCN}, \mathrm{HCl}$ or $\mathrm{HBr}$. The $\mathrm{HCl}$ concentration of $3500 \mathrm{ppm}$ given in the standard is for rat lethality, not incapacitation.

ISO 13571 considers the four major hazards from fire which may prevent escape (toxic gases, irritant gases, heat and smoke obscuration). In essence, it describes the calculation of data relating to the incapacitation of humans exposed to fire effluents. However, it gives no indication as to how these may be combined, except by a general assumption, in a non-normative appendix, that the effects may be estimated independently. Equations 2 and 3 have been taken from ISO 13571. They calculate the FED of 
asphyxiants and the Fractional Effective Concentration (FEC) of sensory irritants for the fire effluent which limits escape. Equation 2 represents the generally accepted case that there are only two significant asphyxiant fire gases $\mathrm{CO}$ and $\mathrm{HCN}$. The FED value is calculated using the exposed dose relationship (concentration-time product, $\mathrm{C} \cdot \mathrm{t}$ ) for $\mathrm{CO}(35000$ corresponds to the incapacitating dose $(\mathrm{C} \cdot \mathrm{t}) \mathrm{for} \mathrm{CO}$ of $35000 \mu \mathrm{l} \mathrm{l}^{-1} \mathrm{~min}$, equal to around $5500 \mathrm{ppm}$ for 30 minutes exposure) and an exponential relationship for $\mathrm{HCN}$ (because asphyxiation by HCN exposure does not fit a linear relationship).

$$
\begin{aligned}
& \mathrm{FED}=\sum_{t_{1}}^{t_{2}} \frac{[\mathrm{CO}]}{35000} \Delta t+\sum_{t_{1}}^{t_{2}} \frac{\exp ([\mathrm{HCN}] / 43)}{220} \Delta t \\
& \mathrm{FEC}=\frac{[\mathrm{HCl}]}{\mathrm{IC}_{50, \mathrm{HCl}}}+\frac{[\mathrm{HBr}]}{\mathrm{IC}_{50, \mathrm{HBr}}}+\frac{[\mathrm{HF}]}{\mathrm{IC}_{50, \mathrm{HF}}}+\frac{\left[\mathrm{SO}_{2}\right]}{\mathrm{IC}_{50, \mathrm{SO}_{2}}}+\frac{\left[\mathrm{NO}_{2}\right]}{\mathrm{IC}_{50, \mathrm{NO}_{2}}}+\frac{[\text { acrolein }]}{\mathrm{IC}_{50, \text { acrolein }}}+\frac{[\text { fomaldehyd e }]}{\mathrm{IC}_{50, \text { fomaldehyde }}}+\sum \frac{[\text { irritant }]}{\mathrm{IC}_{50, \text { irritant }}}
\end{aligned}
$$

Equation 3 uses a similar principle to equation 1 to estimate the combined effect of all irritant gases.

Of particular relevance to this study is the value used for the $\mathrm{IC}_{50 \text {, } \mathrm{HCl}}$ which is given as $1000 \mu \mathrm{l}^{-1}$ or 1000 $\mathrm{ppm}$, in contrast to the estimates of intolerable pain to eyes, nose, throat and chest at $100 \mathrm{ppm}$ discussed earlier and to the $3500 \mathrm{ppm}$ required for rat lethality given in ISO 13344.

\section{Fire Effluent Movement}

An important aspect in the assurance of fire safety is the transport of narcotic and irritant gases in various parts of the building remote from the fire. As smoke moves away from the fire source within a building, it gradually cools and is diluted by the entrainment of air. The concentrations of fire gases remote from a fire may therefore be significantly less than those close to the fire. In most cases, however, they remain present in the same proportions below $600^{\circ} \mathrm{C}$. The two principle exceptions are the equilibrium between $\mathrm{NO}$ and $\mathrm{NO}_{2}$ and gases which deposit during transport. For species such as $\mathrm{HCl}$ whose absorption is dependent on the surface coating of the enclosure this can result in significant losses. Figure 1 shows the rate of decay for $\mathrm{HCl}, \mathrm{HCN}, \mathrm{SO}_{2}$ and $\mathrm{NO}_{\mathrm{x}}$ in a closed cabinet [27]. Two sets of data are shown for $\mathrm{HCl}$, one for a polypropylene (PP) cabinet and one for a mineral fibreboard (MFB) cabinet. The gases were generated by burning materials inside the cabinet where they were retained and the gas concentrations measured.

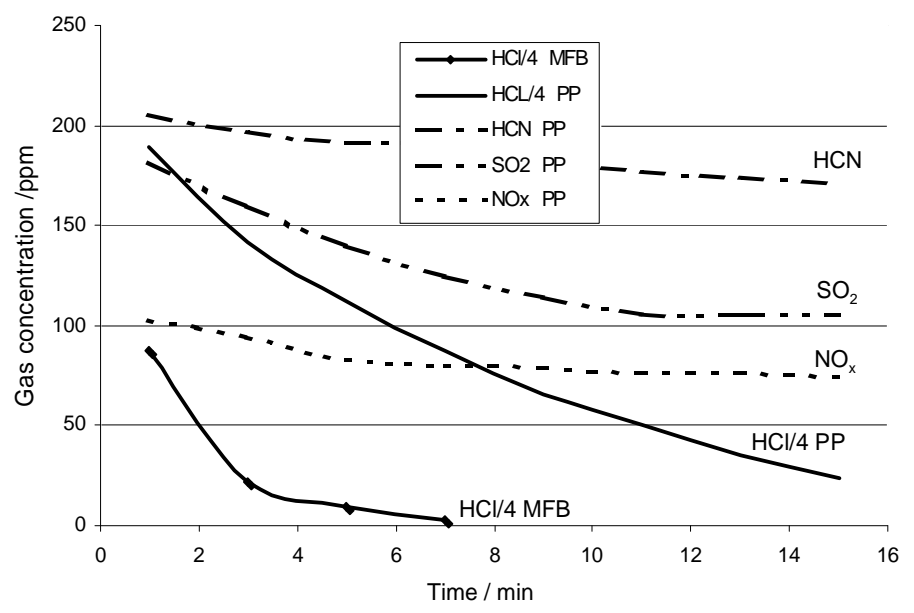

Fig. 1. Decay of fire gases in closed polypropylene cabinet $\left(1.3 \mathrm{~m}^{3}\right)$ and for $\mathrm{HCl}$ also in a mineral fibreboard cabinet.

In another study, the concentration of dry $\mathrm{HCl}$ travelling at $1 \mathrm{~m} \mathrm{~s}^{-1}$ along $120 \mathrm{~m}$ of ventilation ducting $30 \mathrm{x}$ $30 \mathrm{~cm}$ was investigated as a function of wall lining. Unfortunately, all the experiments reported included 
some unpainted gypsum board, and the surface aspect ratio of the duct is unrepresentative of a typical corridor. The fall in $\mathrm{HCl}$ concentration was initially rapid, but then recovered depending on the amount of unpainted gypsum board. However, it was noted that the ability of all materials to absorb $\mathrm{HCl}$ diminished during the 30 minute run, and the experiments were conducted at room temperature, maximizing the adsorption of $\mathrm{HCl}[34]$.

In some of the animal exposure experiments reported earlier, $\mathrm{HCl}$ concentrations were monitored at the point of exposure, in others there are varying degrees of uncertainty as to how much $\mathrm{HCl}$ was lost during transport to the subject. It should also be noted that most animals were exposed to dry $\mathrm{HCl}$ whereas all fire gases contain condensable water vapour. As the fire gases cool, this water may be present as droplets into which the $\mathrm{HCl}$ will dissolve. A further complication arises from the tendency of $\mathrm{HCl}$ to deposit on coalescing soot particles. Although studies in rats and mice have shown similar responses to $\mathrm{HCl}$ aerosols and vapour, the wider respiratory tract of humans and anticipated mouth-breathing may affect this adversely, since droplets have the capacity to penetrate much deeper into the lung than water soluble gases, such as $\mathrm{HCl}$ in a similar way to the PM-10 particles (of $\sim 10 \mu \mathrm{m}$ diameter) present in some polluted urban atmospheres.

The data available for $\mathrm{HCl}$ shows that for humans breathing becomes painful and difficult at $100 \mathrm{ppm}$. For many individuals this pain will reduce the perceived chances of a successful escape. Since most fire victims are not the healthy adults of animal exposure experiments, this may increase the proportion of victims who are trapped by such incapacitating irritants. The animal exposure studies indicate significant differences between species and between experimental protocols. In particular, $\mathrm{HCl}$ exposure appears more survivable by resting subjects than those engaged in physical activity. $\mathrm{HCl}$ exposure during exercise ultimately results in suffocation by animals, who are unable to breathe. The concentrations of $\mathrm{HCl}$ resulting directly in death are much higher than those which will effectively prevent escape, and the more sophisticated approach, which considers both asphyxiation and incapacitation described in ISO 13571 takes this into account. The effect of $\mathrm{HCl}$ in fire gases is complicated by its transport, resulting in a reduction through adsorption on surfaces, but enhanced by deposition onto water droplets and soot, where it can penetrate deep into the lung. As s first approximation, it could be assumed that these two opposing effects might balance each other out.

\section{EXPERIMENTAL}

\section{Bench-Scale Determination of Toxic Product Yields in Fire Effluents}

To quantify the yields of $\mathrm{HCl}$, carbon monoxide and organoirritants from burning PVC, the ISO TS 19700 steady state tube furnace (Purser furnace) [35] was used to generate fire effluent under controlled conditions. The apparatus may be set up to burn material at a particular equivalence ratio $\phi$ (the actual fuel/air ratio divided by the stoichiometric fuel/air ratio), from well-ventilated burning through to forcing a steady state during under-ventilated burning. It does so by feeding the sample and air into a tube furnace at fixed rates, so that the flame front is held stationary relative to the furnace. This enables it to provide reliable data on the product yields as a function of equivalence ratio. Unlike a "flammability test" where a material's chemistry dictates the rate of burning, in the steady state tube furnace all materials are burned at the same fixed rate.

The apparatus is described elsewhere [36], and shown in Fig. 2 with the addition of a secondary oxidiser. Samples are fed into the furnace in a silica boat, travelling at a mass feed rate of $1 \mathrm{~g} \mathrm{~min}^{-1}$. By varying the primary air flow rate different fire conditions were created at known equivalence ratios. Continuous analysis of oxygen depletion and yields of carbon dioxide, carbon monoxide and smoke were determined for each fire condition, at furnace temperatures between $650-800^{\circ} \mathrm{C}$, as previously reported [37]. For the PVC containing materials, hydrogen chloride was collected by drawing a metered volume of fire effluent through three bubblers containing deionised water, and determined using a titrimetric method [37]. In addition, organics were determined, as products of incomplete combustion, by further oxidation at $900^{\circ} \mathrm{C}$ in excess air over silica wool, as the difference between secondary $\mathrm{CO}_{2}$ and primary $\mathrm{CO}$ and $\mathrm{CO}_{2}$. 


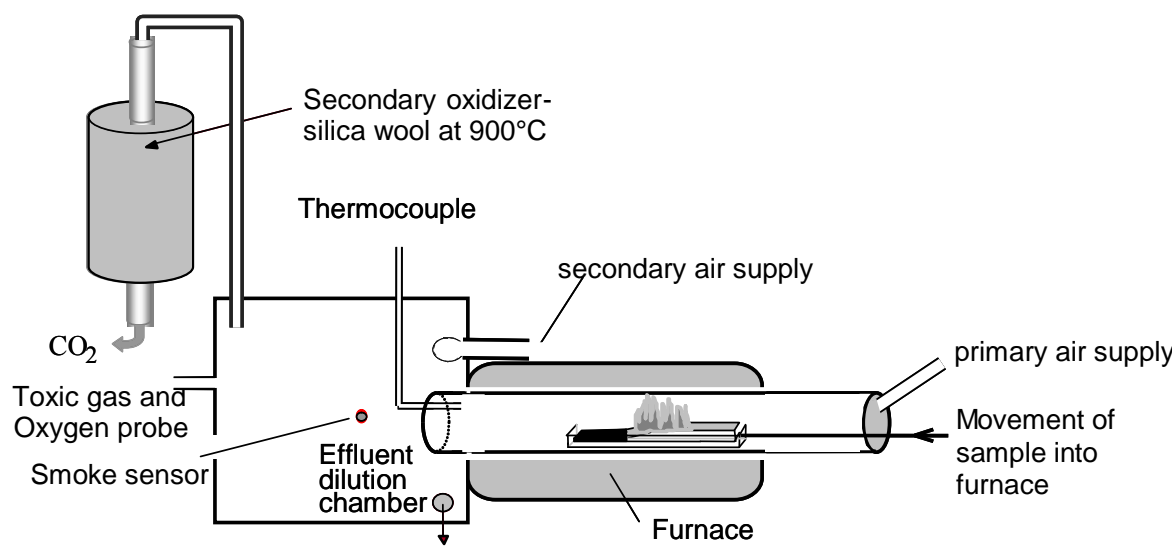

Fig. 2. The steady state tube furnace apparatus (Purser furnace).

\section{The Acid Gas Test - EN 50297-2-3:1998 [38]}

This test has been incorporated into the Euroclassification of cables as part of the Construction Products Directive, introducing an additional acidity classification. This standard uses a simpler apparatus (Fig. 3) in which a static sample is decomposed in a stream of flowing air in the middle of the tube furnace, above $935^{\circ} \mathrm{C}$, and the effluent is collected in bubblers prior to analysis. The acidity of the effluent solution is quantified in terms of $\mathrm{pH}$ and conductivity. In aqueous solution, acids dissociate to give hydrogen ions $\mathrm{H}^{+}$, which give rise to the acidity, measured as $\mathrm{pH}$, the negative logarithm of the hydrogen ion concentration.

In essence, this test identifies the presence of PVC or other halogenated materials in a cable formulation, allowing the two main types of cables used in buildings (PVC based and low smoke zero halogen (LSZH)) to be distinguished.

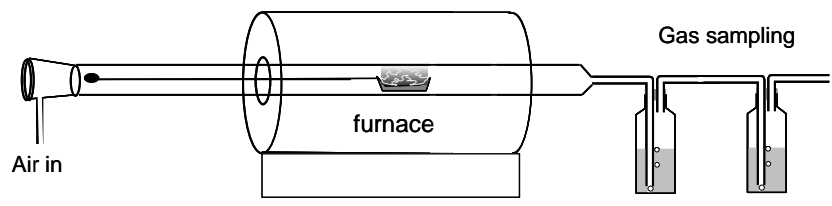

Fig. 3. The EN 50267-2-3 test apparatus.

\section{Materials}

Commercial grades of Low Density Polyethylene (LDPE) and unplasticised PVC (uPVC) were used in pellet form, and the cable samples were used whole. The PVC cable reported in Fig. 4 and Fig. 5 was a commercial formulation which contained PVC, plasticiser and chalk in approximately equal proportions. The cable results shown in Fig. 6 represent a typical selection of widely used PVC and LSZH energy and data cables, and have been described elsewhere [39].

\section{RESULTS}

Fire gas toxicity is a function of both the material composition and the fire conditions. For most materials the fire toxicity increases with decrease in ventilation, but for uPVC there is little change. For clarity, the results presented in Fig. 5 and Fig. 6 refer only to well-ventilated fires. Toxicities are expressed as the effluent generated from burning $1 \mathrm{~g}$ of material in 200 litres of air, based on an established standard [40]. Organoirritants in the fire effluent (measured as the difference in $\mathrm{CO}_{2}$ before and after passing over the secondary oxidiser) were considered collectively using an organic yield of $10 \mathrm{mg}$ litre ${ }^{-1}$ to result in incapacitation, as described by Purser [2]. 


\section{CO Yield from PVC}

In order to investigate another effect of $\mathrm{HCl}$, as an inhibitor of gas phase combustion, reducing the heat release and hence flammability, a series of experiments were conducted on UPVC, PVC cable, and for comparison on LDPE at different equivalence ratios. Each data point represents a separate experimental run, obtained under different ventilation conditions, at furnace temperatures of 650 and $750^{\circ} \mathrm{C}$.

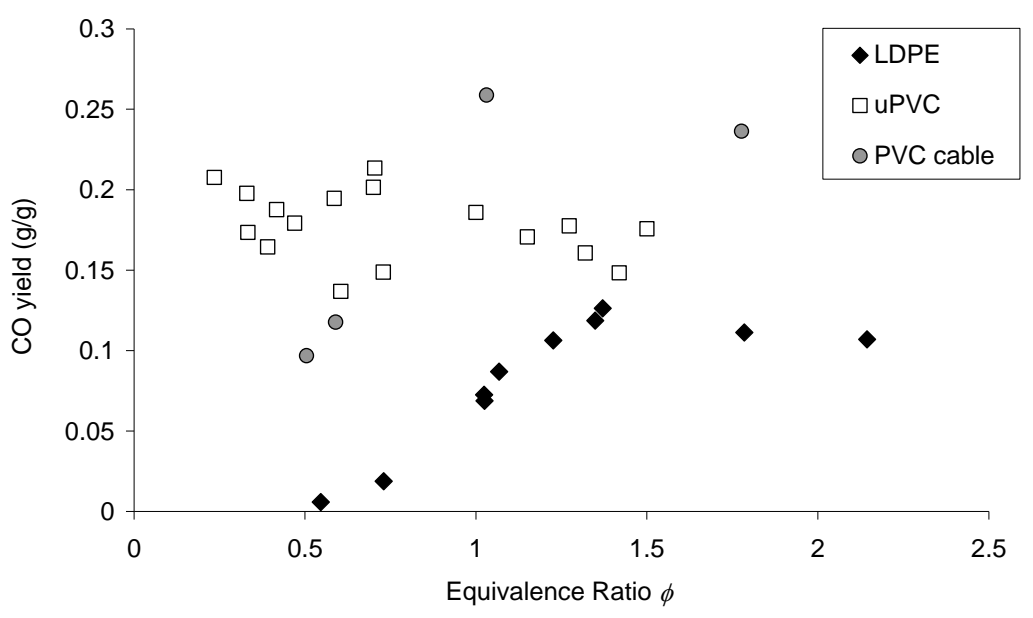

Fig. 4. CO yield for LDPE, uPVC and PVC cable burning in the steady state tube furnace $\left(650-800^{\circ} \mathrm{C}\right)$.

Figure 4 shows the CO yield from UPVC, PVC cable and LDPE as a function of equivalence ratio for the steady state tube furnace. For LDPE and most other common polymers, the CO yield is very low until $\phi=$ 0.7 , then it starts to rise rapidly until $\phi=1.5$, when it usually levels out. This is evident in this data both for LDPE and also for PVC cable. Conversely, for uPVC, a consistently high CO yield is observed even under the most well-ventilated fire conditions, and aside from some scatter in the data, there appears to be a slight reduction in the $\mathrm{CO}$ yield as the flaming becomes under-ventilated.

PVC forms more CO than simple hydrocarbon polymers under well-ventilated conditions because $\mathrm{HCl}$ interferes with the radical chain mechanism [41]:

$$
\begin{aligned}
& \mathrm{HCl}+\mathrm{H} \cdot \rightarrow \mathrm{H}_{2}+\mathrm{Cl} \cdot \\
& \mathrm{HCl}+\mathrm{OH} \cdot \rightarrow \mathrm{H}_{2} \mathrm{O}+\mathrm{Cl} .
\end{aligned}
$$

The high-energy $\mathrm{H} \cdot$ and $\mathrm{OH} \cdot$ radicals are removed by reaction with $\mathrm{HCl}$ and replaced with lower-energy $\mathrm{Cl}$. radicals, which are able to leave the flame without further reaction, or be regenerated by reaction with a hydrocarbon:

$$
\mathrm{Cl} \cdot+\mathrm{RH} \rightarrow \mathrm{R} \cdot+\mathrm{HCl}
$$

Crucially, removal of $\mathrm{OH} \cdot\left(\right.$ and also $\mathrm{H} \cdot$ which generates $\mathrm{OH} \cdot$ ) prevents the conversion of $\mathrm{CO}$ to $\mathrm{CO}_{2}$

$$
\mathrm{CO}+\mathrm{OH} \cdot \rightarrow \mathrm{CO}_{2}+\mathrm{H} \cdot
$$

This reaction is responsible for around half of the heat release. Thus inhibition of flame reactions leads to a higher proportion of products of incomplete combustion, particularly $\mathrm{CO}$, but reduces the heat release. It is interesting to note the higher yields of CO in under-ventilated conditions for the plasticised PVC $(\sim 20 \% \mathrm{Cl}$ content) is higher than that of $\mathrm{uPVC}(\sim 60 \% \mathrm{Cl})$.

\section{Comparison of Toxic Effects Predicted by ISO 13344 and ISO 13571}

Figure 5 shows a comparison of the fire hazard expressed as FED estimated by ISO 13344 (based on rat lethality data) with that from ISO 13571, which omits hypoxia, but includes a separate estimation of incapacitation (FEC), and lethality (FED), for uPVC, a plasticised PVC cable formulation and LDPE. For $\mathrm{uPVC}$ this shows the greater toxicological significance of $\mathrm{HCl}$ over $\mathrm{CO}$, and the much greater effect of the 
$\mathrm{HCl}$ when incapacitation preventing escape, not actual death is used as the end point. It is notable that this large $\mathrm{FEC}$ is obtained using the high $\mathrm{IC}_{50}$ value of $1000 \mathrm{ppm} \mathrm{HCl}$.

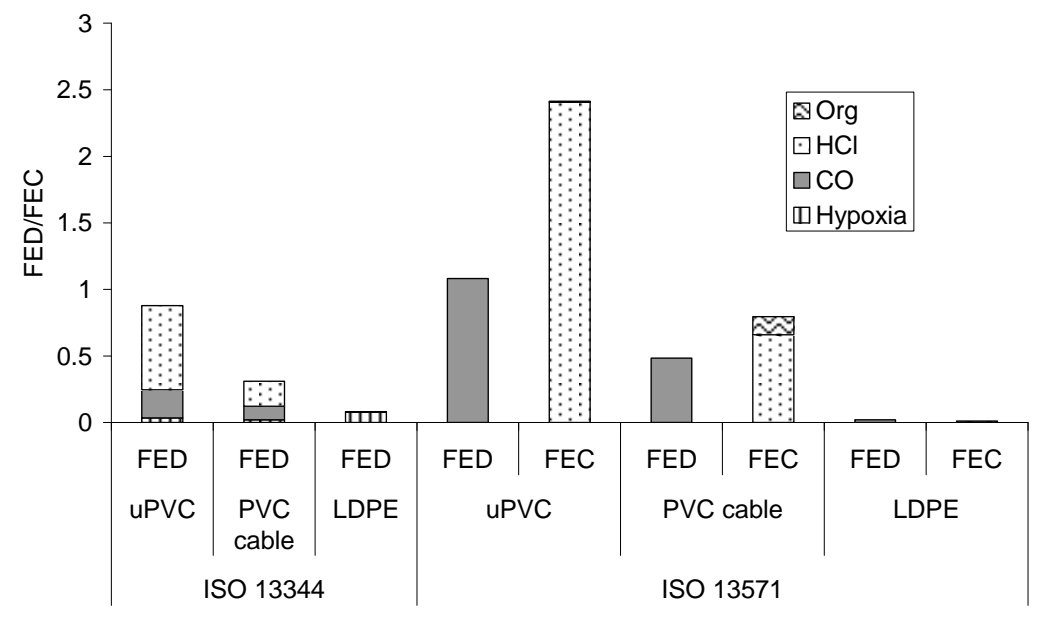

Fig. 5. Comparison of toxic fire hazard assessment from ISO 13344 (based on rat lethality) and ISO 13571 (based on estimates of human incapacitation (FEC) or death (FED)).

In order to demonstrate the relationship between $\mathrm{HCl}$ evolution and the overall toxicity (as quantified using ISO 13344), a series of standard commercial cables were burnt under well-ventilated conditions. The same cables were also decomposed in a small static tube furnace (Fig. 3) and the acidity of the effluent quantified using the EN 50297-2-3 acidity classification method. The results are shown in Fig. 6.

\section{Fire Toxicity of Electric Cables}

The relationship between toxicity (expressed as FED) and acidity (expressed as $\mathrm{pH}$ ) is shown in Fig. 6. For the cables tested, the same two groups appear on the figure. One group gave high $\mathrm{pH}$ values (low acidity), greater than 4 , and correspondingly low toxicity, while the other gave $\mathrm{pH}$ values of 2.5 or less with correspondingly higher toxicity. The change in $\mathrm{pH}$ corresponds to a 50 fold difference in the acidic content.

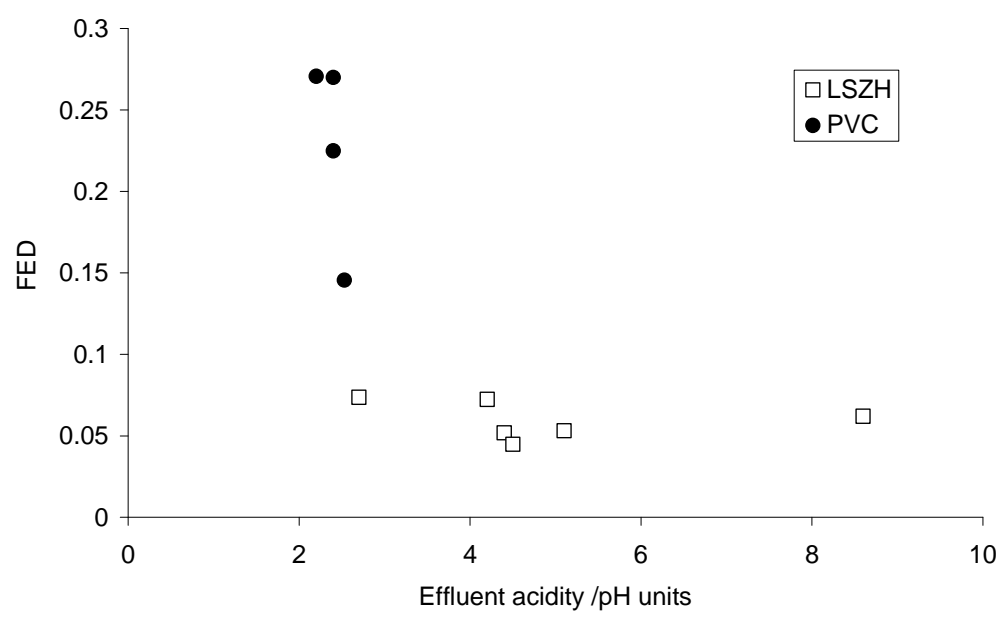

Fig. 6. Variation in toxicity with effluent $\mathrm{pH}$ for standard cables

In both the $\mathrm{pH}$ and toxicity measurements, the four members of the high acidity (low $\mathrm{pH}$ ) and high toxicity group contained PVC and all those in the low toxicity and low acidity group were low smoke zero halogen (LSZH) formulations. For most of the cables tested, the acidity classification is a simple way of discriminating between the two common cable types (LSZH and PVC). For 9 out of 10 of these cables, this 
classification coincides with increased toxicity. However, there are a wide variety of formulations within the two broad types, including many variants which were not part of this study. Although the results give a clear indication of the link, one specific cable fell outside these groups, producing quite a strongly acidic effluent ( $\mathrm{pH}$ 2.7), but very low FED values. Moreover, analysis of the cable shows that it is in fact completely halogen-free and therefore the acid-generating effluent must be non-halogen.

\section{CONCLUSIONS}

$\mathrm{HCl}$ presents two significant hazards in fires, by causing incapacitation through sensory irritancy (leading to painful breathing, swelling of the airways, and ultimately death), and by inhibiting the conversion of CO to $\mathrm{CO}_{2}$. The concentration causing incapacitation, and thus preventing escape, is much lower than that causing death directly; it is considered intolerable to humans at $100 \mathrm{ppm}$ although a value of $1000 \mathrm{ppm}$ given for incapacitation in the ISO 13571 standard. Assigning a "safe level" of $\mathrm{HCl}$ in fire effluents is fraught with difficulties. Incapacitation, preventing escape from a fire, is not quantifiable in animal subjects in the same way as lethality. There is a wide range of responses within a group of animals, and wider differences between different test groups, both within a species and between species. Given the range of physiological and psychological responses of humans to fire effluents, the fire safety community needs to be confident that the level deemed to cause incapacitation will not endanger lives in fires. Transport effects, both in animal exposure studies and in real fires add more uncertainty to the prediction of the time before $\mathrm{HCl}$ will cause incapacitation.

The results demonstrate the increased yield of two of the most easily quantified fire effluents, $\mathrm{CO}$ and $\mathrm{HCl}$, when uPVC is burning, compared with LDPE. They also show differences in the fire chemistry (from increased $\mathrm{CO}$ yield). This manifests itself as a significant increase in the overall estimation of fire toxicity for well-ventilated burning, and, more surprisingly higher CO yields for PVC cable than for the purer uPVC under conditions of reduced ventilation. As an indicator of incomplete combustion, increased $\mathrm{CO}$ yields may be accompanied by the formation of other hazardous organic and organohalogen species, including chloro-aliphatics and mono- and dichlorobenzenes, many of which are more potent sensory irritants than $\mathrm{HCl}$ alone. The effects of these species is corroborated by the difference in response of animal subjects to fire effluents containing $\mathrm{HCl}$ to exposure to $\mathrm{HCl}$ alone. The effect of chlorine on the yields of all toxic and irritant species in different PVC formulations needs to be investigated before more general conclusions can be drawn about the influence of $\mathrm{HCl}$ on fire toxicity. Once these effects have been quantified, and the factors affecting $\mathrm{HCl}$ 's contribution to the overall fire toxicity understood, it may be that $\mathrm{HCl}$ can be used as a marker for a range of fire toxicants. This could lead to a demonstrable relationship between acidity and toxicity, allowing the acidity classification [38] to be used to discriminate between cables of higher and lower fire toxicity.

\section{REFERENCES}

[1] ISO 13571:2007, Life-threatening components of fire - Guidelines for the estimation of time available for escape using fire data, 2007.

[2] Purser, D.A., Toxicity Assessment of Combustion Products, in SFPE Handbook of Fire Protection Engineering 3rd Edition, 2002, 2-117.

[3] Beswick, F.W., Holland, P., and Kemp, K.H., Acute Effects of Exposure to Orthochlorobenzylidene Malononitrile (CS) and the Development of Tolerance, $\mathrm{Br} \mathrm{J}$ Ind Med, 1972, 29, 298-306.

[4] Kaplan, H.L., Grand, A.F., Rogers, W.R., Switzer, W.G., and Hartzell, G.E., A Research Study of the Assessment of Escape Impairment by Irritant Combustion Gases in Postcrash Aircraft Fires, DOT/FAA/CT-84/16 Federal Aviation Administration Washington, 1984.

[5] Alarie, Y., Sensory Irritation by Airborne Chemicals, CRC Crit Rev Toxicol, 1973, 2, 299. doi: $10.3109 / 10408447309082020$

[6] Darmer, K.L., Kinkead, E.R., and DiPasquale, L.C., Acute Toxicity in Rats and Mice Exposed to Hydrogen Chloride Gas and Aerosols, Am. Ind. Hyg. Assoc. J., 1974, 35, 623-631. doi:10.1080/0002889748507082 
[7] Matt, L., Experimental Beitrage Fur Lehre Von Der Entwicklung Giftiger Gase Auf Den Menschen, Doctoral Dissertation, Universitat Wurzburg, 1889.

[8] Henderson, Y., and Haggard, H.W., Noxious Gases and the Principles of Respiration Influencing Their Action, Reinhold Publishing, New York, 1943.

[9] Kane, L.E., Barrow, C.S., and Alarie, Y., A Short Term to Predict Acceptable Levels of Exposure to Airborne Sensory Irritants. Am. Ind. Hyg. Assoc. J., 1979, 40, 207-229.

[10] Alarie, Y., Nielsen, G.D., and Schaper, M., Animal Bioassays for Evaluation of Indoor Air Quality. In: Indoor, Air Quality Handbook (Spengler, J. D., Samet, J.M., and McCarthy, J. F. Eds). McGraw-Hill, New York, 2000, 23.1-23.49.

[11] Barrow, C.S., Alarie, Y., Warrick, J.C., and Stock, M.F., Comparison of the Sensory Irritation Response in Mice to Chlorine and Hydrogen Chloride, Arch. Environ. Health, 1977, 32, 68-72.

[12] National Research Council of the National Academies, Hydrogen Chloride: Acute Exposure Guideline Levels, Acute Exposure Guideline Levels for Selected Airborne Chemicals, Vol. 4, 79, The National Academies Press, Washington, D.C., 2004.

[13] Elkins, H.B., The Chemistry of Industrial Toxicology, 2nd Ed. New York, NY: John Wiley \& Sons. 1959, 79-80.

[14] Purser, D.A., The Application of Exposure Concentration and Dose to Evaluation of the Effects of Irritants as Components of Fire Hazard, Proceedings of the Interflam Conference, Interscience, London 2007.

[15] Kaplan, H.L., Grand, A.F., Hartzel. G.E., Combustion Technology, Principles and Test methods, Technomic Publishing, Lancaster USA., 1983.

[16] Packham, S.C., Behaviour and Physiology: Tools for the Assessment of Relative Toxicity, 17th Annual Cellular Plastics Conference on Safety and Product Liability, Washington, DC, USA 1984.

[17] Pauluhn, J., Toxicity of Fire Effluents, Chapter 16. Plastics Flammability Handbook, Ed J. Troitzsch, Hanser, Germany, 2004.

[18] Flury, F., and Zernick, F., Schadliche Gase: Dampfe, Nebel, Rauch-und Staubarten, Verlag von Julius Springer, Berlin., 1931.

[19] Malek, D.E., and Alarie, Y., Ergometer within a Whole Body Plethysmograph to Evaluate Performance of Guinea-Pigs Under Toxic Atmospheres, Toxicol. Appl. Pharmacol., 1989, 101, 340-355. doi:10.1016/0041-008X(89)90282-2

[20] Sakurai, T., Toxic Gas Tests of Several Pure Gases and Mixed Gases using Mice, Journal of Fire Sciences, Copyright 1989 by Technomic Publishing Co., Lancaster Pennsylvania, 7, Jan/Feb 1989.

[21] Crane, C., Sanders, D., Endecott, B., and Abbott, J., Inhalation Toxicology: IV. Times to Incapacitation and Death for Rats Exposed Continuously to Atmospheric Hydrogen Chloride Gas, Federal Aviation Administration, Civil Aeromedical Institute, Report Number FAA-AM-85-4, May 1985.

[22] Stavert, D.M., Archuleta, D.C., Behr, M.J., and Lehnert, B.E., Relative Acute Toxicities of Hydrogen Fluoride, Hydrogen Chloride, and Hydrogen Bromide in Nose- and Pseudo-MouthBreathing Rats, Fundam. Appl. Toxicol., 1991, 16:636-655. doi:10.1016/0272-0590(91)90152-T

[23] Kaplan H.L., Grand A.F., Switzer W.G., Mitchell D.S., Rogers W.E., Hartzel G.E., Effects of Combustion Gases On Escape Performance of the Baboon and the Rat, J. Fire Sci. 1985, 3, 228244. doi:10.1177/073490418500300401

[24] Kaplan, H.L., Effects of Irritant Gases on Avoidance/Escape Performance and Respiratory Response of the Baboon, Toxicology, 1987, 47:165-79. doi:10.1016/0300-483X(87)90166-1 
[25] Woolley, W.D., Decomposition Products of PVC for Studies of Fires, Br Polymer J, 1971, 3(4) 186-193. doi:10.1002/pi.4980030406

[26] Huggett, C., Levin, B.C., Toxicity of the Pyrolysis and Combustion Products of Poly(vinyl Chlorides): A Literature Assessment, Fire Mater, 1987, 11:131-42. doi:10.1002/fam.810110303

[27] Paul, K.T., Feasibility Study to Demonstrate the Potential of Smoke Hoods in Simulated Aircraft Fire Atmospheres: Development of the fire model, Fire and Materials, 1989, 14, 43-58. doi:10.1002/fam.810140203

[28] Lebek, K., Hull, T.R., and Price, D., Products of burning rigid PVC burning under different fire conditions Fire and Polymers: Materials and Concepts for Hazard Prevention, ACS Symposium Series No.922, p334-347, Oxford University Press, (2005).

[29] Kaplan, H.L., Switzer, W.G., Hinderer R.K., and Anzueto, A., Acute and Long-Term Effects of Polyvinylchloride (PVC) Smoke on the Respiratory System of the Baboon and a Comparison with the Effects of Hydrogen Chloride ( $\mathrm{HCl})$, Journal of Fire Sciences, 1993; 11, 485. doi:10.1177/073490419301100602

[30] Fire Statistics United Kingdom 2004; Office of the Deputy Prime Minister: London, February 2006.

[31] Hull, T.R., Stec, A.A., Lebek, K., and Price, D., Factors Affecting the Combustion Toxicity of Polymeric Materials, Polymer Degradation and Stability, 2007, 92, 2239-2246. doi:10.1016/j.polymdegradstab.2007.03.032

[32] Council Directive 86/609 EEC Article 3.

[33] ISO 13344:1996 Estimation of Lethal Toxic Potency of Fire Effluents, 1996.

[34] Galloway, F.M., and Hirschler, M.M., Comparison of the Results with Predictions from a Theoretical Simulated Heating, Ventilating and Air Conditioning System and Experiments for Hydrogen Chloride Transport and Decay in a Model, Journal of Fire Sciences, 1991, 9, 259. doi:10.1177/073490419100900402

[35] ISO TS 19700:2006 Controlled Equivalence Ratio Method for the Determination of Hazardous Components of Fire Effluents, 2006.

[36] Hull, T.R., Carman, J.M., Purser, D.A., Prediction of CO Evolution from Small-Scale Polymer Fires, Polymer International, 2000, 49, 1259-1265. doi:10.1002/10970126(200010)49:10<1259::AID-PI573>3.0.CO;2-D

[37] Lebek, K., Hull, T.R., Price, D., Fire and Polymers: Materials and Concepts for Hazard Prevention, ACS Symposium Series No.922, p344, Oxford University Press, 2005.

[38] EN 50297-2-3:1998 - Common Test Methods for Cables Under Fire Conditions - Tests on Gases Evolved During Combustion of Materials from Cables, 1998.

[39] Hull, T.R., Lebek, K., and Robinson, J.E., Acidity, toxicity and European cable regulation, Transactions of the International Wire and Cable Symposium (Trans IWCS), 2006.

[40] BS 6853:1999 Code of Practice for Fire Precautions in the Design and Construction of Passenger Carrying Trains, 1999.

[41] Schnipper, A., Smith-Hansen, L., Thomsen, E.S., Reduced Combustion Efficiency of Chlorinated Compounds, Resulting in Higher Yields of Carbon Monoxide, Fire and Materials, 1995,19, 61-64. doi:10.1002/fam.810190203 